\title{
La presentación social del cuerpo marroquí en contextos migratorios. Entre la afirmación identitaria y el rechazo islamófobo ${ }^{1}$
}

\author{
The Social Presentation of the Moroccan Body \\ in Migratory Contexts. Between the Identity \\ Affirmation and the Islamophobic Rejection
}

\author{
Yolanda Aixelà \\ Institució Milà i Fontanals. CSIC. Barcelona
}

\section{RESUMEN}

Este artículo analiza la presentación social del cuerpo de los hombres y mujeres marroquíes en su país y en situación migratoria con el objetivo de observar los usos e interpretaciones del vestido y el impacto que tienen en su integración social y en la visibilidad del Islam en España y otros países europeos. Algunas de las conclusiones apuntan a la afirmación identitaria personal, religiosa y nacional de quienes siguen ciertas normas vestimentarias y prácticas corporales, aunque su elección vaya a tener repercusiones islamofóbicas en contextos migratorios.

Palabras clave: Vestido, Velos, Marroquíes, Islamofobia, Mujeres, Hombres, Inmigración.

\section{SUMMARY}

This article aims to analyze the social presentation of the body of the Moroccan women and men in their country and in migration with the objective to observe the use and the interpretation of clothing and the impact that it has in their social integration and in the Islam's visibility in Spain, and other European countries. Some conclusions

${ }^{1}$ Este artículo es el resultado de una investigación de larga duración vertebrada y financiada por diferentes proyectos: "La presentación social del cuerpo en el contexto de la globalización y la multiculturalidad", 2007-2010, I+D SEJ2007-60792, dirigido por Josep Martí (IMF-CSIC); y, posteriormente, Proyecto Intramural “Cuerpo y cultura en África central. Un análisis pluricultural y transnacional", 2008-2009, № 200810I102, dirigido por Yolanda Aixelà (IMF-CSIC); y "La gestión de la diversidad cultural y el impacto sociopolítico de las migraciones transnacionales en dos ex-colonias españolas: Guinea Ecuatorial y Marruecos", 2011-2014, I+D HAR2011-22752, dirigido por Y. Aixelà (IMF-CSIC). 
point out the affirmation of personal, religious and national identity, from who respect some clothing rules and body practices, although their election has islamophobia repercussion in migratory contexts.

Keywords: Clothes, Veil, Moroccan, Islamophobia, Women, Men, Immigration.

\section{LA PRESENTACIÓN SOCIAL DEL CUERPO EN CONTEXTOS DE ORIGEN Y EN SITUACIÓN MIGRATORIA}

El objetivo de este artículo es analizar el grado de afirmación identitaria individual y colectiva que implica el uso de ciertas vestimentas y cuidados corporales entre el colectivo marroquí en situación migratoria.

Como veremos, el uso de ciertas prendas como chilabas, gellabas, combinadas entre las mujeres con alguno de los tipos de velos existentes, especialmente el hiyab, y entre los hombres una cierta estética de bigotes y/ o barbas combinada con el casquete de tela semiesférico tagiyya, y más inusualmente por el casquete de tela cilíndrico, tarbush, o el turbante, imamah, forma parte de una tradición cultural en los países de origen que, en contextos migratorios, homogeneíza al colectivo árabe y beréber musulmán sin distinción de nacionalidad, y que se interpreta como un seguimiento fidedigno del Islam. Esta vestimenta propicia rápidas identificaciones, muchas de ellas equívocas porque la adopción de una presentación social del cuerpo concreta puede fundamentarse en motivaciones diversas, existiendo, incluso, distinciones en los usos y significados que la población española desconoce porque carece de los conocimientos para descodificarlas. Así, la visualización de hombres y mujeres marroquíes vistiendo estas prendas emerge como una metáfora de la conjunción existente entre vestido y cultura (Kasriel 1989), provocando una colectivización masculina y femenina que se aleja de los matices biográficos y personales. Como resultado, se produce un efecto largamente criticado en países europeos respecto al velo femenino musulmán que viene siendo acusado de invisibilizar a las mujeres: la vestimenta tradicional resta identidad individual a quien la porte. Así, el efecto sobre la ciudadanía del seguimiento de una presentación del cuerpo concreta por parte del colectivo marroquí, o magrebí en general, es que se presuponen y estereotipan sus motivaciones, intereses personales y proyectos de futuro.

Otra de las repercusiones de la adopción de estas fórmulas vestimentarias en estos tiempos de aumento de la islamofobia en España y Europa es que la colectivización y homogeneización de hombres y mujeres de religión musulmana conducen a una agudización de la otredad del Islam que crea 
distancias culturales irreductibles entre "ellos" y "nosotros", cuando las identidades de hoy, española o europea, han crecido también con valores e influencias de diferentes países de mayoría musulmana. Estos juicios de valor se siguen produciendo a pesar de que, como señalaba Roy (2003), Europa también es musulmana, en la línea de la compilación de Al Sayyad y Castells (2003) o Tohidi (2003: 152) para quien se debería dar mayor profundidad al tratamiento de la cuestión de la mujer en el Islam, no sólo porque occidente produce conocimiento, sino porque actualmente los musulmanes conviven con los europeos y, de hecho, entre las nuevas generaciones se es musulmán y europeo al mismo tiempo. Por su parte, Ramírez (2011) también incidía en el efecto de dominación sobre las mujeres que se podía ejercer desde la islamofobia, en la línea trazada por Amiraux (2003) y otros.

Es relevante que el uso del velo por las mujeres, en mayor proporción que el uso de vestimentas tradicionales por los hombres, es también debido a una mayor necesidad de afirmar su fe a través del vestido. Conviene no olvidar que la asistencia femenina a las mezquitas es mucho menor que la de los hombres, entre otras cosas porque en éstas no siempre se ha reservado un espacio dedicado a las mujeres. Por tanto, el seguimiento personal e individual de la fe religiosa por parte de las mujeres puede conllevar una necesidad de hacer pública y manifiesta su adhesión al Islam. Los hombres pueden darla a conocer a través de una asidua asistencia a las mezquitas que para ellas es más complicada, no sólo por carecer de espacios sino también por su responsabilidad respecto a la familia y la prole en el hogar. De hecho, muchas mujeres marroquíes, o magrebíes, residentes en España y Europa comenzaron a velarse en el último lustro para contrarrestar las críticas que recibe el Islam en las sociedades receptoras de migración: su presentación social del cuerpo es una toma de posición frente a la estigmatización que el Islam viene sufriendo, y su elección de vestir velos las aleja del preponderante discurso que anteriormente se hacía de su situación. Ahora bien, el uso del velo no sólo tiene un sentido religioso vehiculado a través del cuerpo, sino también numerosas funciones, como privatizar segmentos de espacio público, mostrando así efectos espaciales y no sólo corporales (Lewis 2007; Aixelà 2010), al tiempo que expresa una moda y un consumo concreto del colectivo femenino musulmán (Lewis 2007: 424).

En este texto se quiere destacar que esa primera percepción de la otredad masculina y femenina marroquí que se tiene en contextos migratorios españoles, y por extensión en muchos países europeos, está dificultando la percepción de objetivos personales, especificidades colectivas y proyectos comunitarios alejados de los estereotipos sociales que siguen circulando sobre el Islam. Hay que incidir en la capacidad de conferir identidad que el vestido ha tenido históricamente en los contextos musulmanes (Marín 
2001), a pesar de que, como constataba Moors (2011: 148) al revisar la imagen colonial para comprender ese rechazo a la indumentaria de algunos musulmanes: "Dress regulations that employed a Western Aesthetic and removed signs of religion from public were a means to present the nation as modern and civilised".

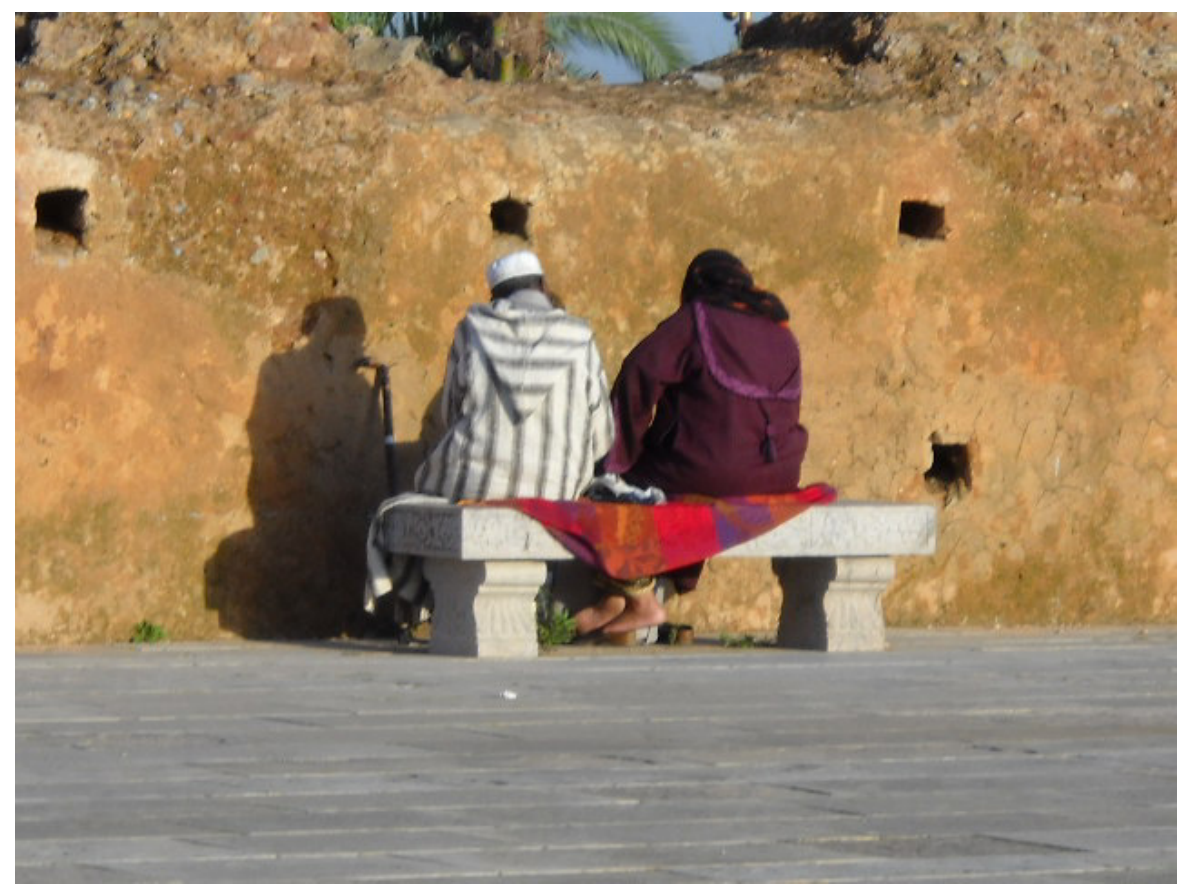

FiguRA 1.-Pareja anciana en Tour Hassan, Rabat. Diciembre de 2009. Foto de Y. Aixelà.

Una presentación social del cuerpo concreta no sólo está entrelazada con la afirmación religiosa, sino también con una estética masculina y femenina de largo recorrido histórico en sus países ${ }^{2}$, que se encuentra en especial auge en la última década, tanto en contextos de origen como en aquellos que son receptores de esta inmigración ${ }^{3}$. Todo ello, en unos años en que el is-

${ }^{2}$ Se recomienda la lectura del volumen editado por Manuela Marín (2001) y del libro de Dolores Serrano-Niza (2005). Otra dimensión sobre el cuerpo viene abordada en Maribel Fierro y Francisco García Fitz (2008).

${ }^{3}$ Se recomienda la lectura de Koskennurmi y otros (2004), quienes analizan el uso de ciertas vestimentas en Finlandia por mujeres musulmanas de muy distintas procedencias geográficas, no sólo árabes. 
lamismo político moderado sigue obteniendo una especial visibilidad en el parlamento marroquí (Zeghal 2006; Aixelà 2009c), al tiempo que, según algunas informaciones, el gobierno marroquí parece querer garantizar el sentimiento de pertenencia a su identidad nacional a pesar de haber migrado a un país europeo ${ }^{4}$.

Por todo ello, a lo largo de este texto se abordarán los cuerpos masculinos y femeninos simbólicos, imaginarios, sexuados, espaciales y politizados en un juego de espejos que pretende reflejar motivaciones y prácticas de marroquíes en origen y destino migratorio. La premisa principal es que la presentación social del cuerpo de las mujeres sigue emergiendo como la frontera social y religiosa del encuentro con personas de otras culturas, tanto en Marruecos como en España. Esta tarea cuenta hoy con un incipiente refuerzo masculino, dado que, si la visibilidad del Islam, especialmente desde mediados del siglo XX y con el auge de unas independencias coloniales necesitadas de afirmación identitaria, había sido una responsabilidad exclusivamente femenina, hoy podría estar empezando a ser también masculina con la adopción de ciertas vestimentas.

Los cuerpos, masculinos y femeninos, albergan la capacidad de simbolizar la cultura en el Islam. Y cabe reseñar que esa presentación social del cuerpo concreta puede dificultar su integración social, porque puede acelerar su exclusión, despertar la negatividad en el entorno disparando algunas alarmas sobre la posibilidad de la convivencia en la diversidad, todo

${ }^{4}$ Al respecto el 2 de agosto de 2011 El País publicó un artículo sobre la estrategia del gobierno marroquí frente a la migración de sus conciudadanos titulado "Marruecos utiliza la religión para controlar a sus inmigrantes en España: http://www.elpais.com/ articulo/espana/Marruecos/utiliza/religion/controlar/inmigrantes/Espana/elpepiesp/ 20110802elpepinac_1/Tes (consultado en julio de 2011). Otro artículo interesante analizaba la renovación de la fe como forma de reproducción de la identidad. El País, 2 de agosto de 2011: "Marruecos ha elaborado 'una estrategia de gran magnitud' en España. Diseñada y desarrollada por el régimen, su objetivo es extender su influencia e incrementar el control sobre las colonias marroquíes utilizando la excusa de la religión", subraya el Centro Nacional de Inteligencia (CNI) en un informe secreto remitido en mayo por su director, el general Félix Sanz Roldán, a los ministros de Interior, Exteriores y Defensa. Los ministerios del Interior y de Justicia comparten esta opinión del servicio secreto. Rabat "tiene como objetivos prioritarios el control de su colonia [unas 760.000 personas, a las que hay que añadir otras 70.000 que adquirieron la nacionalidad] para detectar movimientos opositores al régimen y evitar la aparición de corrientes islamistas ajenas a la dominante" en Marruecos, señalan en otro informe confidencial elaborado conjuntamente en 2009. La "principal herramienta de control que emplea Rabat es, según el CNI, la Federación Española de Entidades Religiosas Islámicas...”. Sobre el papel de la mezquita en la cohesión de la comunidad marroquí en Alicante, se puede consultar Aixelà (2007). 
ello a pesar de que estas personas se asentaron en unas sociedades flexibles y heterogéneas en cuanto a diversidad cultural.

\section{CONDICIONAMIENTOS SOBRE EL CUERPO EN MARRUECOS Y EN ES- PAÑA. ANALOGÍAS ENTRE CUERPO, ISLAM Y CULTURA DESDE UNA PERSPECTIVA DE GÉNERO}

La manera de presentar el cuerpo refleja un modo de posicionarse en sociedad. Como señalaba Martí (2008: 19):

Els canvis socials estan sovint marcats també pels canvis en la presentació del cos, i els canvis en la presentació del cos duen a canvis socials. La presentació del cos, a més d'expressar pertinença, marca sempre un posicionament, tant des del punt de vista personal, com també social i polític, segons els grups o collectius als quals hom s'adscriu o es deixa adscriure.

En Marruecos, las nociones sobre el cuerpo y su presentación social, tienen una dimensión sociocultural, religiosa, política y de género que requiere un análisis pluridimensional, puesto que más allá de identificaciones simplistas, están asentados en tradiciones históricas. Desde una perspectiva sociocultural, la presentación social del cuerpo de hombres y mujeres está vinculada también a una concepción del espacio en el que lo público es eminentemente masculino y lo doméstico femenino, al tiempo que para las mujeres se prioriza su papel en la familia como esposa y madre frente al de proveedores y protectores para los hombres. En ese sentido los velos, del tipo que sean, han facilitado la incorporación de las mujeres al espacio público, mostrando aparentemente la aceptación de sus actividades prioritarias en el seno de la familia ya que se privatizaban segmentos de espacio público. Por ello, tal como veremos, la construcción de género para las mujeres que potenciaba la maternidad encontró en el velo un cómplice que salvaguardaba el honor familiar en el espacio público. Desde una dimensión religiosa, las mujeres veladas honraban con su pudor a las mujeres musulmanas ya que se interpretaba que eran buenas creyentes, mientras que los hombres con responsabilidades concretas en las mezquitas han seguido siendo modelo para el resto de la comunidad masculina musulmana.

$\mathrm{Y}$ es que las vestimentas masculinas y femeninas tales como la chilaba, el tagiyya o el biyab tienen una dimensión histórica incuestionable (Marín

\footnotetext{
${ }^{5}$ Este hecho ha afectado directamente a las mujeres conversas en España que necesitaban demostrar más que otras su fidelidad al Islam. Sobre las conversas españolas ver el trabajo de Margarita del Olmo (2003).
} 
2001), que presenta continuidades hasta la actualidad. Estas vinculaciones entre identidad sociocultural y presentación social del cuerpo tomaron especial relevancia durante el período colonial y el inicio del postcolonial, momento en que la ritualización del cuerpo se reforzó en el Magreb, tal como mostró Chebel (2004): se hizo relevante la presentación social de hombres y mujeres, se acentuaron las normas que la regían y se enfatizaron las prohibiciones que la condicionaban. El cuerpo era metáfora de la cultura. Para Chebel, esta situación estaba provocada en parte por la presencia europea, ya que los magrebíes necesitaban distinguirse de los colonizadores para afirmar su alteridad. Las mujeres fueron parcialmente protagonistas en este proceso de afirmación identitaria colectiva, tal como propugnaron algunos personajes influyentes como Allal al-Fasi en el caso marroquí en lo que se refiere a la promoción del uso del velo.

Una de las conclusiones de nuestro estudio es que parece que en la Europa actual se está repitiendo el proceso, sólo que esta vez los hombres participan junto con las mujeres en la consolidación y continuidad de sus especificidades socioculturales: el uso de ciertas vestimentas promociona y consolida la identidad árabe o beréber musulmana en situación migratoria.

Por tanto, la concepción cultural del cuerpo entre los marroquíes y magrebíes es compleja y poliédrica. Algunas de las claves más importantes que permiten entender las tradiciones corporales son las vinculaciones existentes entre el Islam y el género, el parentesco, el derecho o la concepción del espacio ${ }^{6}$. La coexistencia de todos estos aspectos es lo que está asegurando que las regulaciones sobre el cuerpo entre los marroquíes sean transmitidas de generación en generación, siendo el Islam uno de los ejes fundamentales que condicionan la construcción de las identidades corporales masculinas y femeninas en esta área geográfica y en situación migratoria.

\section{ISLAM, GÉNERO Y CUERPO}

Las sociedades magrebíes proporcionan una imagen homogénea de la construcción social de los sexos. Ello se debe a que la fuente principal del Islam, el Corán, establece ciertas actividades prioritarias a partir de la complementariedad sexual. Los hombres son protectores y proveedores de la familia, mientras las mujeres son ante todo madres y esposas. Como señalaba Schleifer (1996: 51) en un libro que tenía como objetivo promocio-

\footnotetext{
${ }^{6} \mathrm{Al}$ respecto, ver el análisis sobre el cuerpo en Marruecos que realiza desde la perspectiva de género la tesis doctoral de Araceli González Vázquez (2010). Ver también para terminología Aguadé y Benyahia (2005).
} 
nar el Islam en USA: "Muslim women sees pregnancy, childbirth, nursing and rearing as a spiritual act. It is her exclusive opportunity to obtain Allah's blessings and rewards, as the difficulty of pregnancy and childbirth is a way wich Allah has allotted only to the female sex". La construcción de género refuerza la maternidad como prioridad femenina, lo que va a tener efectos en ciertas cuestiones relacionadas con el embarazo (por ejemplo, el "niño dormido" o bou mergoud), el penalizado aborto, la importancia de dar el pecho (lo que se puede alargar hasta los dos años), o el dar a luz. De otro lado, la esterilidad culpabiliza a los dos sexos, aunque tiene efectos más directos en las mujeres, que se enfrentarán fácilmente a un divorcio o repudio en tanto que el cuerpo femenino se vincula a su capacidad de procrear. Estos aspectos condicionan que muchas mujeres perciban que la función principal de su cuerpo sea la maternidad y que, por tanto, deba ser preservado.

\section{ISLAM, RELIGIÓN Y CUERPO}

Esta analogía condiciona de distinta manera a hombres y mujeres, dado que establece prácticas corporales concretas ${ }^{7}$. De un lado, la relación es normativa en el colectivo masculino, ya que el rito iniciático de la circuncisión es imprescindible para formar parte de la comunidad de creyentes, umma. De otro lado, hay una relación simbólica entre Islam-religión-cuerpo en lo femenino, porque el lslam se ha venido visualizando a través de las mujeres, especialmente de aquellas que llevaban algún tipo de velo. Ellas se erigieron como las guardianas de la identidad colectiva y se han convertido en fuentes de legitimidad islámica y de consolidación identitaria. Como prueba del papel de las mujeres en la afirmación colectiva, aparecen las dificultades para transformar los códigos de familia en el mundo arabomusulmán (Aixelà 2009a; 2009b) o el tipo de discursos emitidos desde los islamismos radicales (Aixelà 2009c). Las mujeres continúan hoy simbolizando la autenticidad islámica.

En situación migratoria esta simbología mujer-velo no sólo persiste, sino

\footnotetext{
${ }^{7}$ Una obra interesante al respecto es la de Josep Lluís Mateo Dieste (2010), donde se analiza el concepto de persona en el mundo arabo-musulmán en una reflexión que no ha proliferado en exceso, a pesar de ser necesaria para obtener un panorama general de las maneras de pensar de las personas en este contexto, y que constituye uno de los capítulos más originales del libro, junto, con el de las concepciones plurales de enfermedad y curación, y el de los jnun. Estos temas también son tratados de forma novedosa y con numerosos ejemplos etnográficos por Araceli González (2010).
} 
que tras los atentados terroristas, que han conllevado el empeoramiento de la imagen de lo musulmán en el mundo, se ha acentuado como forma de defender el legado del Islam. Por otro lado, la práctica de la circuncisión masculina en contextos europeos se desarrolla sin ningún tipo de dificultad, permitiendo cumplir el requisito masculino más importante para sumarse a la comunidad de creyentes (de la misma importancia que entre los judíos).

\section{ISLAM, PARENTESCO Y CUERPO}

El parentesco en contextos árabes y beréberes musulmanes es el de la filiación unilineal patrilineal (una de las excepciones son los tuareg). Este tipo de filiación proporciona mayor prestigio y visibilidad a los hombres que a las mujeres y refuerza la importancia de tener hijos varones porque ellos son los que van a asegurar la filiación y la herencia.

La patrilinealidad es un elemento que indirectamente puede generar una exaltación de la figura masculina como detentadora del prestigio social y como representante del grupo. Estos aspectos han influido en algunos de los conceptos clave, extensamente trabajados por la antropología del mediterráneo, "honor" y "vergüenza". Como se expone en esta propuesta teórico-metodológica, y concretamente desde la perspectiva de Bourdieu (1972: 35): "la femme, être faible, impure et maléfique", se decía que podría conducir a la desgracia del grupo de parentesco. En este marco teórico, la virginidad y la fidelidad femeninas eran importantes porque "la femme étant toujours 'la fille d'un tel' ou 'l'épouse d'un tel', son honneur se réduit à l'honneur du groupe des agnats auquel elle est attaché. Aussi doit-elle veiller à n'altérer en rien par sa conduite le prestige et la réputation du groupe" (Bourdieu 1972: 37). El cuerpo femenino debía ser protegido del exterior y ello conllevaría una división espacial:

L'opposition entre le dedans et le dehors... s'exprime concrètement dans la distinction tranchée entre l'espace féminin, la maison et son jardin, lieu par excellence du haram, espace clos, secret, protégé, à l'abri des intrusions et des regards, et l'espace masculin, la thajma'th, lieu d'assemblée, la mosquée, le café, les champs ou le marché (Bourdieu 1972: 36).

En ese sentido, las vestimentas que cubrían a las mujeres como el haik, las chilabas o el velo, protegían el honor familiar, en un sentido que se considera anterior al del velo que visualizaría el Islam del período colonial y postcolonial.

En situación migratoria esta simbología aún está presente, por cuanto parte del colectivo marroquí interpreta el vestido femenino en términos de 
protección del honor y como forma de expresar pudor frente al encuentro con extraños.

\section{ISLAM, FUENTES JURÍDICAS Y CUERPO}

El derecho islámico, fiqh, a través del Corán, los hadices y la Sunna, condiciona cierta presentación social del cuerpo. Para el hombre, la barba y el bigote son signos de sabiduría, madurez, experiencia y erudición, gracias al modelo de Mohamed el Profeta y posteriormente de imames u otros líderes religiosos. La barba y el bigote simbolizan al hombre perfecto y completo, lo que para Tazi (1998: 27-28) es señal inequívoca del retorno a la influencia de la religión en la sociedad y en la política. Para la mujer, se recomienda el recato, que cubra su cuerpo, y se hace referencia al velo de las esposas del profeta, utilizado para distinguirse del resto de mujeres en un precedente recuperado como fuente de legitimidad en la promoción del uso del hiyab. En otro texto Aixelà (2010) puse de relieve la influencia del Islam normativo en estas cuestiones. Asimismo, el Corán estipula las partes del cuerpo que son tabú: por ejemplo, el vientre, entre las rodillas y los pechos. También quedan afectados ciertos flujos corporales: la menstruación y el esperma son tabú, mientras que la sangre y la leche materna tienen la característica de transmitir parentesco. Estos aspectos fueron abordados por Chebel (2004). Por último, el cuerpo también está condicionado por una alimentación con algunas prohibiciones, como el total desangrado de los animales que van a ser ingeridos o el rechazo del cerdo. También en ciertas prácticas festivas religiosas, como el Ramadán, las prohibiciones sobre el cuerpo incluyen el ayuno, la no ingesta de agua, el no mantener relaciones sexuales, etc., hasta que se ponga el sol.

En situación migratoria esta simbología se mantiene, tanto los tabúes asociados al cuerpo, como otras prohibiciones. De hecho, la Comisión Islámica aprobó en 1991 un acuerdo que permite, desde las instancias españolas, respetar las especificidades musulmanas que repercuten en la vida cotidiana. Y es que, en general, los rituales y la asistencia a celebraciones también renuevan la identidad colectiva que, en situación migratoria incorpora pocos cambios porque los rituales asociados, tales como la circuncisión, o ciertas fiestas religiosas como el Ramadán ${ }^{8}$ o festividades naciona-

\footnotetext{
${ }^{8}$ El seguimiento del Ramadán es una obligación y un deber que compromete a los creyentes personalmente y que se acompaña en sus países de origen por una legislación con consecuencias penales en caso de transgresión pública. El Ramadán es una de las maneras de manifestar la fe y la creencia en Allah por lo que es muy difícil que un
} 
les, como el Aid al Kabir se reproducen, si bien la menor presencia de parientes puede propiciar que se deban celebrar con amistades o en privado y en la intimidad, lo que resta fuerza a la celebración para algunos migrantes.

\section{ISLAM, ESPACIO Y CUERPO}

Esta vinculación de espacio y cuerpo se presenta desde dos perspectivas. Por un lado, existe una distinción sexual, según la cual el espacio masculino es el exterior, el de la mezquita, el café, las calles; y el espacio femenino es el de la casa, que está acotado y protegido, y que cuando se traspasa requiere el uso del velo. Por otro lado, está la socialización del cuerpo desde la infancia, ya que son las mujeres las que introducen a los niños y las niñas en el conocimiento del cuerpo, quienes les visten, les lavan, les curan. También son las mujeres las que les llevan al baño público, hammam, hasta que los niños evidencien su curiosidad por las mujeres, momento en que irán con sus padres en el horario masculino.

En situación migratoria la división del espacio por sexo se suaviza, aunque no entre los recién llegados, básicamente porque se trata de una sociedad nueva, una ciudad desconocida, en la que usualmente no tienen familiares o amigos que les acompañen y asesoren en su cotidianidad. Distinto es para los hijos de los migrantes que han nacido y crecido en el nuevo medio, que no tienen porqué aceptar algunas de las costumbres de los países de origen de sus padres.

musulmán practicante renuncie al seguimiento de esta práctica, además porque se trata de un esfuerzo colectivo que encuentra el ánimo en todas las miradas cómplices de las personas que le rodean. A ello se suma que la voluntad individual recibe numerosas presiones sociales para respetar el Ramadán, en primer lugar de la familia en el hogar, pero obviamente también de los vecinos, los amigos, los clientes, los compañeros de trabajo y, por supuesto, del Estado allí donde las leyes supervisen su cumplimiento. Quebrantar pues el Ramadán es muy complicado ya que constituye uno de los cinco pilares del Islam. Dicho esto, cabe señalar que los musulmanes que migran a otros países sin mayoría islámica encuentran un entorno diferente durante este período: no hay presión ni supervisión social que les delate o les recuerde que faltan al seguimiento de la fiesta, como sí sucede en sus sociedades de origen, hecho que, en principio, podría facilitar el quebrantamiento de lo que consideran su obligación, lo que, aún así, no convence a una parte para renunciar a su cumplimiento. 
III. CUERPOS MIGRANTES: SIMILITUDES EN LAS VESTIMENTAS MASCULINA Y FEMENINA EN CONTEXTOS DE ORIGEN Y CONTEXTOS MIGRATORIOS

Una presentación social concreta del cuerpo define una manera de integrarse en sociedad desde una identidad personal elegida. Más allá de corresponder a un babitus bourdiano, hace tangibles las formas de pensar el mundo y pone las bases para una búsqueda de afirmación identitaria en coordenadas históricas y socioculturales concretas.

En contexto migratorio, el uso de ciertas vestimentas puede ser una señal entre otros migrantes, ya que se les hace saber que se pueden mantener algunas tradiciones, aunque se viva en un país distinto, al tiempo que pueden expresar una respuesta a la (escasa) integración, ya que con el simple uso de unas prendas y una presentación social del cuerpo concreta, puede promocionar una forma de integración colectiva. El hecho es aún más notable si se tiene en cuenta que debajo de las chilabas, sus ropas son de estilo europeo por lo que no hay renuncia a un tipo de vestido, sino que se da prioridad a uno frente al otro, y también a lo que representa.

En la figura 2 se aprecia la vestimenta cotidiana femenina en Marruecos, mientras, que la figura 3 muestra vestimentas en situación migratoria.

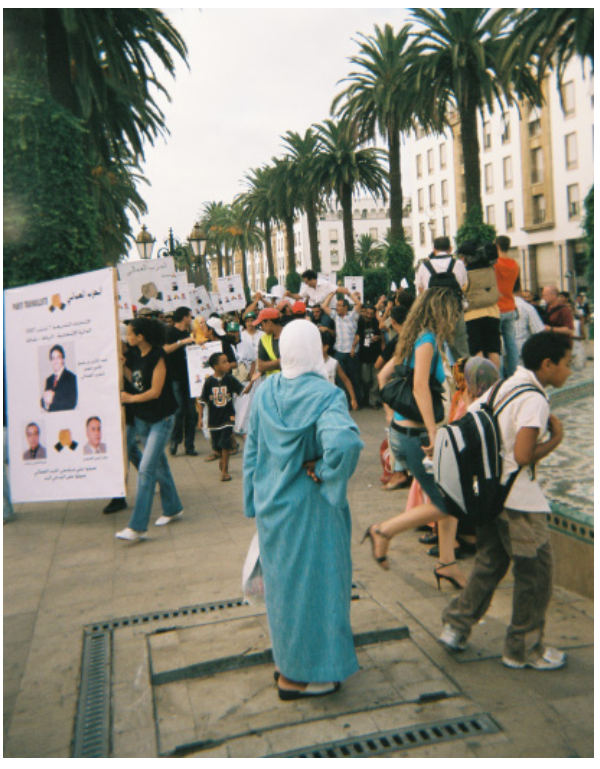

FIgURA 2.-Mujer ante el Parlamento marroquí de Rabat. 2008. Foto de Y. Aixelà.
Así, la presentación con prendas tradicionales tiene un efecto en la comunidad marroquí y magrebí, ya que su uso genera una sensación de continuidad (coincida o no con la realidad de las biografías personales); el vestido acalla la conciencia colectiva frente al cambio y presupone el seguimiento de unos valores y consignas, ciertas o no. En realidad, la integración del colectivo marroquí en España es relativa, si se tiene presente que sus círculos de amistad más próximos son mayoritariamente conciudadanos, signo inequívoco también de que podrán mantener alguna de sus 
tradiciones y prácticas culturas con mayor facilidad. Algo distinta es la situación de sus descendientes nacidos en España que se integran con mayor facilidad, aunque a menudo vayan a carecer de las mismas oportunidades que los autóctonos.

Una de las conclusiones de esta investigación es que una presentación social del cuerpo con símbolos difíciles de disociar de tradiciones socioculturales y vestimentas musulmanas agudiza las dificultades de integración del colectivo marroquí y magrebí inmigrado. Ello se debe a que el seguimiento

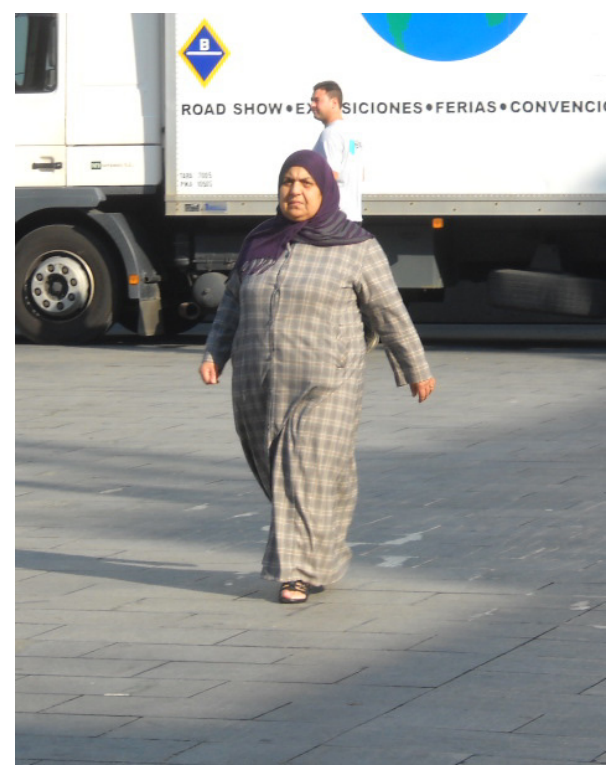

FiguRA 3.- Hiyab, Barcelona. Julio de 2011. Foto de Y. Aixelà. de ciertas prácticas de vestido y corporales ha renovado el compromiso con un pasado cultural, al tiempo que ha afirmado su identidad en un contexto de destino en el que mayormente se rechaza la adscripción musulmana, en parte por construirse sobre un imaginario colectivo resultado de siglos de desencuentro sociocultural (Martín Corrales 2002).

Como señalaba Baumann (1999), una integración rápida en contextos migratorios es aquella que garantiza la invisibilidad, el anonimato, la indiferencia. Pero la presentación social del cuerpo de algunos marroquíes consigue el efecto contrario. Por tanto, destaca la sorprendente voluntad de todos aquellos que, aún sabiendo que el efecto que conseguirán con su forma de presentar el cuerpo será la exclusión, continúan con sus hábitos indumentarios y corporales. Para buena parte de los marroquíes y magrebíes que siguen estas prácticas, su acción renueva la identidad, el sentimiento comunitario y la fe musulmana, todo un éxito que no requiere ni movilización social, ni eco mediático, ni proselitismo: el simple hecho de vestir de acuerdo a ciertas consignas es la mejor propaganda de cómo integrarse en los contextos migratorios, al tiempo que recibe el apoyo admirado de aquella parte de la comunidad que piensa y actúa como ellos. 


\section{Presentación social del Cuerpo de hombres y mujeres en Marruecos}

La chilaba, gellaba, usada en Marruecos, tanto por hombres, como por mujeres, es el vestido de uso cotidiano, substituido en el caso de las mujeres por el antiguo haik o jaique que era una gran tela de lino, normalmente blanca, con el que se envolvían el cuerpo y en ocasiones la cara. Hay chilabas para invierno y para verano que cambian el tipo de tejido utilizado, más liviano o abrigado dependiendo del clima. Otras prendas utilizadas en las ocasiones festivas por las mujeres son los caftanes, si bien en el caso de los hombres siguen usando chilabas de tejidos más nobles. En diferentes regiones encontramos otras prendas, como los mandiles en el caso del Rif marroquí que las mujeres se anudan a la cintura encima de otras ropas y, con los que también se cubren la cabeza. El calzado acostumbra a ser la babucha, tanto para hombres como para mujeres que, de acuerdo a sus adornos, pueden ser utilizadas a diario o en ocasiones festivas. De hecho alguna de estas prendas ha sufrido transformaciones en Marruecos (Vicente 2001). En ese sentido hay que incidir en que la tradición del vestido se instituyó en los primeros siglos del Islam (Tottoli 2001) y que a partir de ahí, la indumentaria ha ido transformándose y diversificándose. En cualquier caso, proporciona información codificada sobre la persona, su clase social, su grupo étnico, su origen rural o urbano, que puede estar también supeditada a las opciones personales de quien la viste (Marín 2001).

Respecto a la percepción social del uso de alguno de los velos, cabe reseñar la encuesta realizada en Marruecos en 1995 por Bourquia, El Ayadi, Harras y Rachik (2000) que ponía de relieve la ausencia de rechazo al biyab. De hecho, Bourquia (2000: 52) mostró que el 58’3\% de los jóvenes estaba a favor de su uso. Por sexos, las jóvenes eran las que más lo defendían con el 60'8\%, frente al 54'8\% de ellos. Según los datos de Rachik (2000: 254n), el 63\% de los encuestados manifestaron que sus esposas vestían a la europea y que sólo el 16\% llevaba hiyab.

En la presentación del cuerpo de los hombres aparece una afirmación religiosa y una dimensión política, especialmente en el caso de los personajes influyentes que marcan tendencias. Cabe destacar que en el caso del Rey de Marruecos, el atuendo puede variar de acuerdo al público al que se dirija o a las reuniones que deba mantener, optando en ocasiones por una vestimenta europea. 
Figuras eminentes de la sociedad marroquí

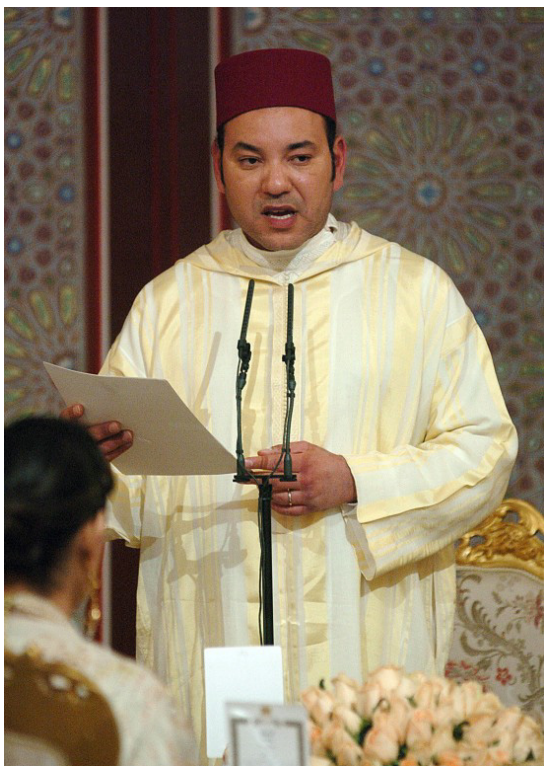

FIGURA 4.-Mohamed VI vistiendo chilaba y tarbush o fez ${ }^{9}$.

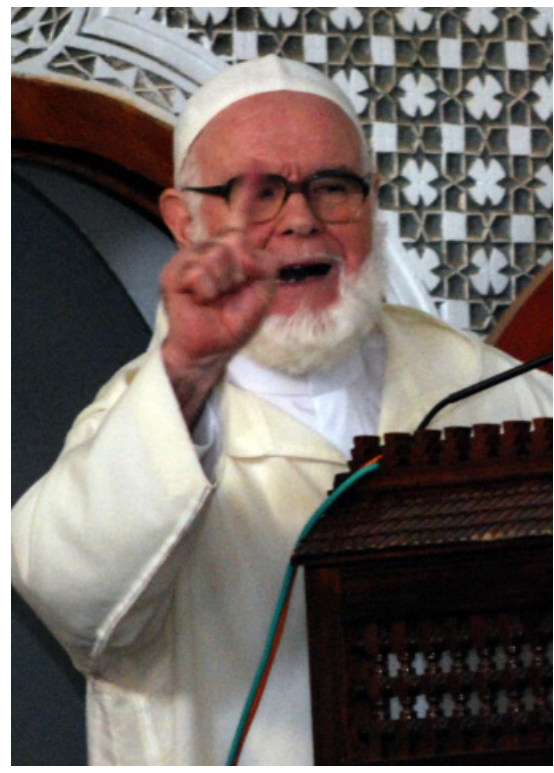

FIGURA 5.--Imam Mohamed Zaqlul, imam en Sidi Embarek vistiendo chilaba y tagiyya ${ }^{10}$.

En general, los hombres utilizan las chilabas y los casquetes cilíndrico, tarbush, o semicónico como la tagiyya, siendo más excepcional el turbante, imamah. Entre los varones se refuerza el cuerpo imaginado a través de los testimonios sobre el Profeta Mohamed, mientras que para las mujeres el modelo es el cuerpo oculto (Aixelà 2010). Cuando se desea dar una dimensión religiosa a la vestimenta se elige el blanco o los colores ocres.

2. PRESENTACiÓN SOCIAL DEL CUERPo FEMENiNO EN SITUACiÓN MigRATORIA Y TIPOS DE VELOS

En contexto migratorio, las prendas que más se han extendido entre las

${ }^{9}$ Fotografía disponible en: http://lamp02.entravision.com/Media/images/Mohamed-VIpide-la-normalizacion-de-las-relaciones-con-Argelia.jpg

${ }^{10}$ Fotografía disponible en: http://www.elfarodigital.es/ceuta/sociedad/3192-el-imamde-sidi-embarek-reclamo-ceuta-para-marruecos-el-pasado-viernes.html 
mujeres que desean afirmar su identidad o hacer visible su tradición sociocultural son los velos, con bastante variedad en tipos (y colores asociados a cada uno), y no las chilabas. A continuación vamos a presentarlos, si bien no todos son utilizados por las mujeres marroquíes en España o en otros países europeos, además de que las diferentes prendas representan distinto compromiso respecto a la fe musulmana (lógicamente, es más comprometido vestir el nikab que el hiyab).

Una cuestión clara es que se produce un uso generacional de los velos: la moda del velo arrasa entre las jóvenes ${ }^{11}$, pero no entre mujeres de 35 años en adelante, que los eligen de colores menos llamativos, aunque también los combinen con la ropa ${ }^{12}$, sino entre chicas desde los quince años hasta entrada la veintena, que aprovechan para vestirlos y llamar la atención con ellos. De hecho, una parte de la juventud que lo lleva combina

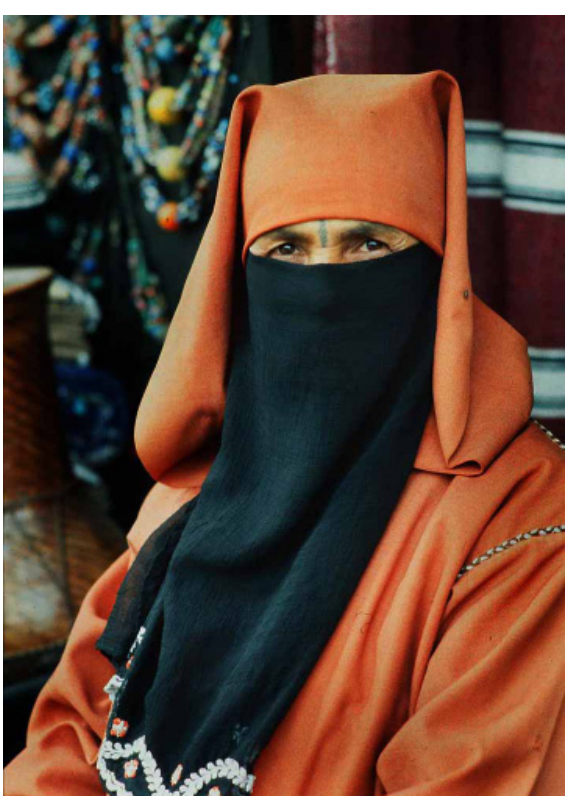

FIgURA 6.-Mujer marroquí con el litam $^{13}$. su uso con ropa muy ajustada, lo que sería reprobable para algunos líderes comunitarios, ya que se considera que la vestimenta de las mujeres debe ser suficientemente holgada para difuminar la silueta corporal.

El litam es un pañuelo o velo que cubre la boca y la nariz, que habitualmente se combina con una chilaba con capucha. Es propio de Marruecos y abunda poco en España.

El niqab cubre la cara dejando hueco para los ojos y es siempre negro. En Europa está principalmente presente en Francia y Reino Unido. Usualmente se combina con una túnica negra que cubre todo el cuerpo.

\footnotetext{
${ }^{11}$ Lewis (2007) ofrece un interesante análisis sobre la moda del velo en Londres.

${ }^{12}$ Se pueden consultar diferentes páginas web de venta de vestimenta para mujeres musulmanas. Algunas son http://www.hijabjewels.com/category_1/Amira-Hijab.htm; Por ejemplo en la web http://www.thehijabshop.com/ además de vender prendas de ropa de muchos colores, formas y estampados, explican como se viste el hiyab (http:// www.thehijabshop.com/information/how_to_wear.php). Consultado en julio de 2011.

${ }^{13}$ Foto de Steve Evans disponible en: http://www.flickr.com/photos/babasteve/5687993/
} 


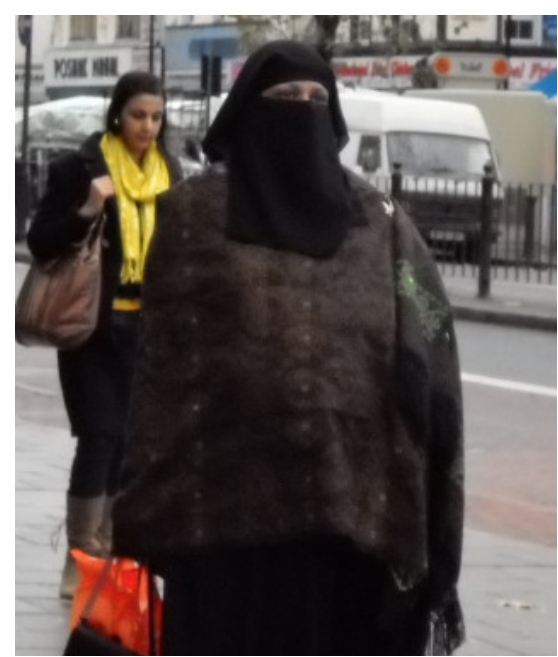

FIGURA 7. Mujer en los alrededores de la mezquita East London un viernes para la oración. Londres. Noviembre de 2009. Foto de Y. Aixelà.

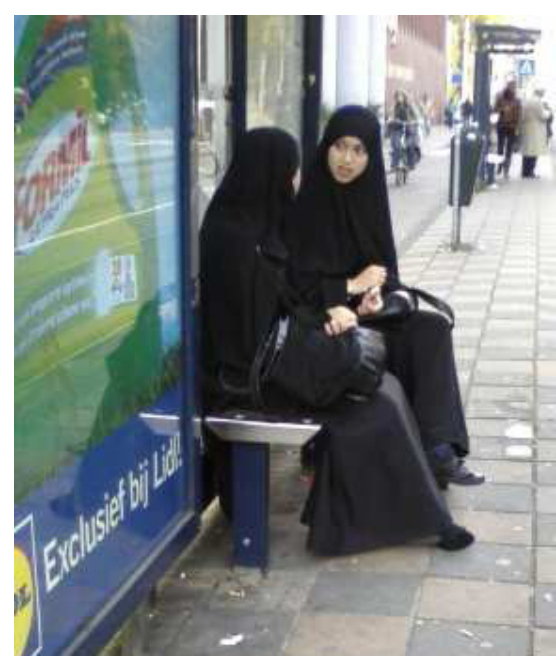

FIGURA 8.-Amsterdam. Esperando el tranvía. Octubre de 2009. Foto de Y. Aixelà.

El jimar es un velo que cubre la cabeza y cae por debajo de los hombros.

El hiyab es un velo que cubre el pelo y las orejas, que se recoge por el cuello completamente o cayendo parcialmente por los hombros y colgando por la espalda.

El al-amira está compuesto de dos piezas. Una, a modo de gorro, que se ajusta totalmente a la parte superior de la cabeza, la otra es una suerte de bufanda a modo de tubo que se adapta a todo el contorno de la cabeza y cuello ${ }^{14}$.

El shayla es un velo o pañuelo que cubre la cabeza, se envuelve en el cuello, cayendo uno de sus extremos a la altura del pecho. Es un pañuelo rectangular que se puede llevar de distintas maneras, aunque una de las más comunes es cubriendo la cabeza girando sobre el cuello. Es el tipo de velo que más podemos ver en España junto al biyab.

Otros velos característicos de otras zonas geográficas musulmanas son el burka y el chador. El burka afgano consiste en una túnica de cuerpo completo que cubre incluso los ojos, permitiendo la visión a través de una

\footnotetext{
${ }^{14} \mathrm{Si}$ se consultan los foros de musulmanas (como http://www.musulmanas.org) se puede observar cómo algunas españolas conversas al Islam prefieren usarlo al principio porque es más fácil de poner y no requiere alfileres a los que no están acostumbradas.
} 


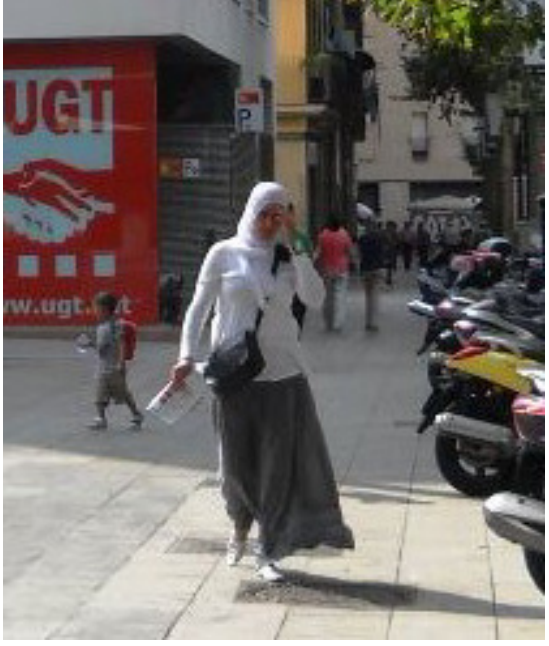

FIgURA 9.-Barcelona. Julio de 2011. Foto de Y. Aixelà. redecilla calada, y que suele ser de color gris o azul. Por su parte, el chador iraní es una túnica semicircular negra que cubre casi todo el cuerpo, dejando un hueco para la cara. Es característico de los chiíes de Irán.

3. La PRESENTACIÓN SOCIAL DEL CUERPO MASCULINO EN SITUACIÓN MIGRATORIA: TAGIYYA Y CHILABAS

En contexto migratorio, algunos hombres usan chilaba, pero muchos menos que los que la utilizan en su localidad de origen, en parte porque es una ropa incómo-

da para algunas de sus profesiones y también porque la presión laboral de los jefes puede ser mayor que las que reciben las mujeres (buena parte de ellas se dedica al servicio doméstico). No siempre es fácil acceder a estas ropas en la emigración y muchos hombres y mujeres aprovechan los establecimientos abiertos por conciudadanos, cuando no algún viaje propio o de un familiar, para adquirir las ropas que desean. De hecho, es importante destacar que en situación migratoria se pierden las diferencias regionales en la vestimenta, tal vez porque el acceso a las prendas concretas es más complicado. La mayoría de los hombres utiliza sobre todo ropa europea, salvo cuando acuden a la mezquita o a algún ritual importante. Y es que la mayoría de la población masculina en situación migratoria renuncia a su vestimenta tradicional, salvo algunos ancianos, durante los actos vinculados a la mezquita, especialmente los viernes o en ocasiones especiales, o cuando se asiste a ciertas festividades comunitarias o familiares.

\section{Persistencias, Cambios E interpretaciones SOBRe El Vestido}

El uso de ciertas vestimentas por parte de los hombres ha despertado menos polémica que las que utilizan las mujeres, probablemente porque en Europa hace más de un siglo que se viene denunciando la subordinación femenina en una sumisión simbolizada a través del velo, siendo ésta una de las armas empleadas para denunciar el "atraso cultural" de estas sociedades y 
culpabilizar directa o indirectamente al Islam. Algunas de las valoraciones que se repiten por parte de la sociedad autóctona es que estas mujeres están oprimidas, que vestir el velo muestra su subordinación a los hombres, que visten el velo por la religión, que quieren vivir aquí igual que viven allí, que están privadas de su propio cuerpo, que el velo es reflejo de la esclavitud, que son unas ignorantes, etc. Algunas de estas afirmaciones nos remitirían a la reflexión sobre que el velo no es tanto producto de la subordinación de las mujeres, como el efecto de la misma. Como señalaba Butler (2006: 41) "es a través

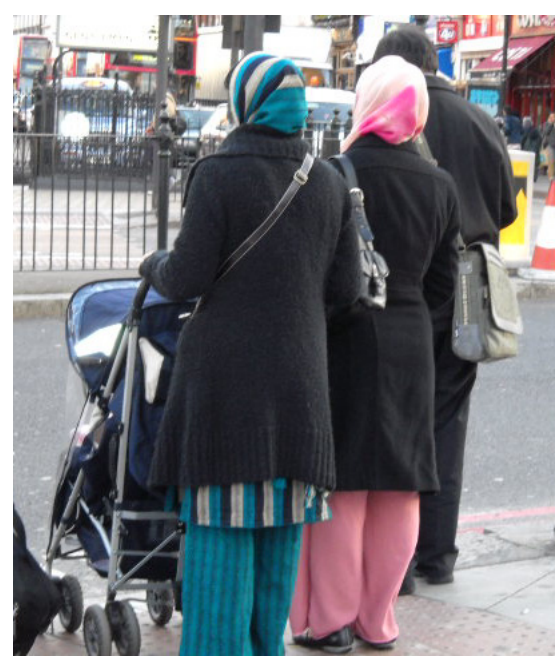

FIGURA 10.-Londres. Velos conjuntados con las ropas. Noviembre 2009. Foto de Y. Aixelà. del cuerpo como el género y la sexualidad se exponen a los otros".

Ciertamente, buena parte del rechazo social que sufren los musulmanes en general, y las mujeres en particular, se centra en la presentación social del cuerpo de aquellas mujeres que adoptan un vestido y complementos propios de sus contextos de origen (aunque deberíamos reflexionar sobre esa óptica, sobre si el velo produce la subordinación o si es el efecto de la misma). Y es que en el imaginario europeo existe una estrecha relación entre patriarcado e Islam que lleva a estereotipar las particularidades de los hombres y mujeres marroquíes. Ello ha permitido que durante mucho tiempo se desculpabilizara a las mujeres de las prendas que vestían, al considerarlas víctimas de la opresión masculina, patriarcal e islámica, argumento que, como veremos, actualmente está cambiando.

Por otro lado, muchas de las jóvenes musulmanas hijas de padres marroquíes que portan algún tipo de velo, lo acompañan con ropa muy ceñida, incluyendo tejanos, pero siempre a juego con su hiyab a través de una conjunción de colores o telas, con una cara maquillada en ojos y labios, llamando la atención. Visten el velo "a la moda". ¿Se podría afirmar que la feminidad de estas jóvenes marroquíes está anulada por el uso del hiyab? La respuesta, en estos casos, sería mayoritariamente que no, especialmente entre las jóvenes que más cuidan su aspecto, aunque probablemente presente variaciones respecto a muchas otras, también adultas, que ni visten el biyab ni su indumentaria se diferencia de la del resto de ciudadanía, porque buscan una invisibilidad que les permita pasar desapercibidas en el medio en el que viven. 
La situación que se produce es totalmente inversa a la que generaba el uso del velo en sus contextos de origen en los años 1980 y 1990, ya que entonces era el hiyab el que facilitaba su incursión en el espacio público, por cuanto homogeneizaba al colectivo y relativizaba a la persona. No como en Barcelona, y también en otros contextos europeos, donde portar el hiyab puede ser interpretado por parte de la ciudadanía como un símbolo de rebelión frente a las normas españolas y de afirmación de la identidad islámica en un ámbito cristiano Moreras 1999; 2008).

En España, y en Europa, se ha pasado de la victimización de las mujeres que llevaban el velo, porque se pensaba que era el efecto de una imposición masculina familiar, a la culpabilización y al rechazo de las que lo visten, por considerar que es un desmarque inmerecido de la sociedad de acogida. Por eso, si en el pasado reciente las mujeres marroquíes eran vistas como víctimas, diez años más tarde se piensa lo contrario: muchas escogen el velo por decisión propia. Por tanto, islamofobia y controversia por la vestimenta femenina han ido aumentando desde el atentado del 11 de septiembre de 2001 en Nueva York. Como señalaba Saliba (2002: 1):

The image of a veiled woman captioned 'The Face of Islam' appears in striking juxtaposition to photos of the crubling Twin Towers of the World Trade Center. Features in a New York Times photo essay of the year 2001, these oft-repeated media images link the oppresion of Muslim women to terrorist violence.

También Ramírez (2011: 12) incidía en el tema:

La liberación de las mujeres se ha convertido en una parte fundamental de las argumentaciones que sostienen diversas formas de dominación. La construcción desde Europa de las mujeres musulmanas está basada en una representación corporal del que el hiyab forma parte.

Algunos de los argumentos que las mujeres marroquíes que viven en Barcelona esgrimen en su defensa es que vale la pena vestir el biyab aunque sepan que van a sufrir el rechazo de los autóctonos, porque son más respetadas por los miembros de su comunidad. Algunas señalan que tienen muchas ganas de ponérselo, "sé que soy fuerte para mantener mi identidad de musulmana ante todos". Algunas otras se quejan de tener que quitárselo para trabajar. Otras creen que es su mejor manera de ser religiosa, porque consideran que la ropa para la musulmana es para mostrar la fe y para practicar la rectitud: "nos queremos distinguir de las que no creen". En cualquier caso, para esta investigación, es muy relevante que en los discursos, marroquí o europeo sobre las mujeres, se acabe responsabilizando injustamente a las mujeres de la consolidación o estancamiento de la sociedad musulmana, tanto en sus países como en el extranjero. 


\section{POLÍTICAS Y PERCEPCIONES DE LOS MARROQUÍES Y MAGREBÍES EN ALGUNOS PAÍSES EUROPEOS}

En diferentes países europeos se ha estado polemizando sobre la integración de los inmigrantes musulmanes. Se trata de un colectivo muy visible por sus características vestimentarias (chilaba, velos y tagiyya), en ocasiones acompañadas por hábitos corporales masculinos como barba y bigote. Tienen restricciones alimentarias (cerdo y alcohol) y prácticas higiénicas, religiosas y festivas ritualizadas que celebran a menudo de forma comunitaria (el Ramadán). Estas diferencias culturales se hacen explícitas y visibles, dificultando el anonimato y la indiferencia que facilitan la integración de los migrantes en Las sociedades de acogida. Estos aspectos se combinan con el histórico distanciamiento entre Islam y Occidente, que tuvo una renovada tensión tras el ataque terrorista de Nueva York y los sucesivos acaecidos en ciudades europeas, que para algunos confirmaban la creación de una identidad supranacional islámica, con un número cada vez más alto de musulmanes con nacionalidades europeas.

Así, algunos países, con Francia a la cabeza, llevan años legislando sobre la construcción de mezquitas para evitar su proliferación, y sobre el uso del hiyab, especialmente en las escuelas, con el deseo de imponer las normas estatales y romper con la reproducción de ciertas tradiciones culturales y religiosas que podían repetirse en parte de la descendencia de migrantes procedentes de países arabo-musulmanes. Las restricciones sobre el uso de algunos tipos de velos femeninos y la dificultad de construir nuevas mezquitas han venido siendo señales inequívocas del rechazo a lo musulmán en la mayoría de países europeos. Una de las últimas discusiones que han emergido en diferentes países durante el año 2010 se ha centrado en la restricción del uso del velo femenino integral en los espacios públicos. Diferentes Estados se han pronunciado sobre el particular, si bien obtuvo menos eco la declaración de la Unión Europea en junio de 2010 que no sólo decidió descartar las iniciativas para prohibir el velo desde su parlamento, sino que aprovechó para rechazar las normativas que estaban surgiendo en diferentes estados miembros ${ }^{15}$.

De hecho, se da la paradoja de que el Islam en Europa también se está visualizando a través del colectivo femenino, como en Marruecos o el Magreb: el cuerpo femenino con el uso del velo, proporciona homogeneidad a los países musulmanes y favorece la posible transnacionalidad musulmana.

\footnotetext{
${ }^{15}$ La noticia fue divulgada en ABC y está disponible en: http://www.abc.es/20100628/ sociedad/bruselas-burka-201006281332.html (consultado en julio de 2011).
} 


\section{EL CASO FRANCÉS}

El desencuentro francés con las prácticas musulmanas y el velo femenino se remonta a finales de los años 1980 si bien no ha sido hasta 2011 cuando ha entrado en vigor una ley que prohíbe el uso del velo integral en espacios públicos. Tal como informaba el periódico ABC en su edición del 17 de julio de 2010, bajo el título "Francia aprueba por abrumadora mayoría prohibir el uso del burka en los espacios públicos":

Tras un largo debate nacional, la Asamblea Nacional ha adoptado por 335 votos a favor y uno en contra el proyecto de Ley que prohibirá el velo integral islámico o burka en todos los espacios públicos a partir de enero del 2011 [...] Según la ministra de Justicia, Michèle Alliot-Marie, redactora del texto final, la nueva Ley tendrá un carácter esencialmente "disuasivo" y "pedagógico", con multas muy modestas, de 150 euros, acompañadas de unos "cursillos de educación cívica nacional", en caso de "resistencia" u oposición. Por el contrario, la "instigación" a llevar el velo islámico integral podrá castigarse con hasta 30.000 euros.

Y es que Francia ha sido rotunda al definir los derechos universales de mujeres y niños, e históricamente se ha mostrado muy crítica con los países del mundo arabo-musulmán en este sentido. Se considera que en este contexto cultural las mujeres carecen de derechos, poder y autoridad en las esferas pública y privada. Una de las críticas más controvertidas es la vinculación establecida entre velo, mujer e Islam, al considerar que las mujeres musulmanas que visten esta prenda están sometidas a su familia y a su cultura. También hace pocos años que se prohibió cualquier símbolo religioso en las escuelas, polémica decisión que tuvo como resultado negar el derecho universal de los niños a la educación, en favor del derecho "universal" a la laicidad de los ciudadanos franceses. Las niñas que acuden veladas a las escuelas son expulsadas: ¿Contradicciones de la modernidad? Asimismo, recientemente se celebró el primer juicio a mujeres que acudieron a un ayuntamiento vestidas con el niqab ${ }^{16}$.

\section{El CASO BRITÁNICO}

El caso británico se sitúa más cercano al marco del multiculturalismo estadounidense del melting pot, según el cual se permite que los diferentes

\footnotetext{
${ }^{16}$ El Mundo, 16 de junio de 2011 "Primer juicio en Francia por llevar el velo integral", disponible en: http://www.elmundo.es/elmundo/2011/06/16/internacional/1308243621.html (consultado en julio de 2011),
} 
colectivos desarrollen su identidad a partir de sus propias coordenadas socioculturales. Esta perspectiva ha permitido que los colectivos magrebíes que residen en diferentes ciudades (poco numeroso respecto a otros grupos de musulmanes migrantes) no hayan tenido dificultades en el mantenimiento de ciertas prácticas y en la elección de una presentación del cuerpo determinada, lo que no ha evitado que en Gran Bretaña haya un sentimiento de rechazo a lo musulmán, tal como constató Webner (1996: 115) en los años noventa: "[...] anti-Muslim or antiimmigrant sentiments and practices persist in Britain".

Así, en el Reino Unido no exis-

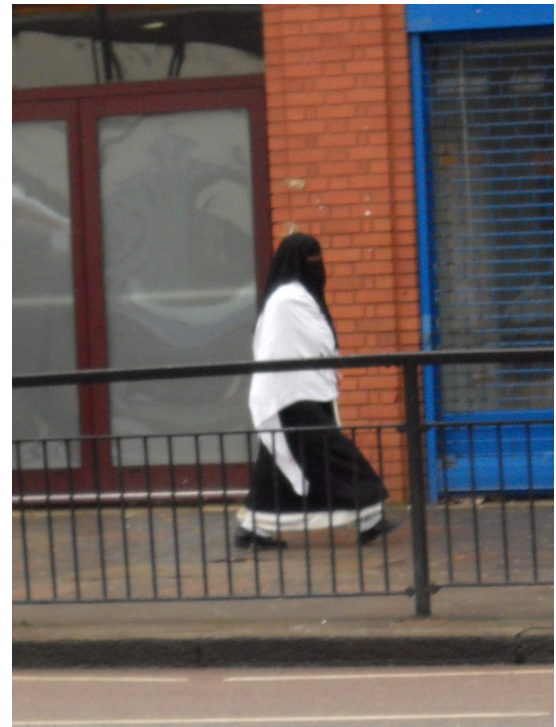

FIGURA 11.-Mujer entrando en la mezquita East London un viernes para la oración con la indumentaria preceptiva. Londres. Noviembre de 2009. Foto de Y. Aixelà. te prohibición sobre el atuendo islámico, si bien las escuelas pueden decidir sobre su código de vestimenta, a raíz de una sentencia en que los tribunales fueron forzados a tomar una decisión cuando una estudiante se quejó porque su escuela la envió a su casa por usar una túnica que cubría todo su cuerpo, excepto sus manos, sus pies y su rostro ${ }^{17}$. Ciertamente, esa flexibilidad del Estado británico había variado ligeramente tras el atentado de Londres del 7 de julio de 2005, ya que, para Lewis (2007: 438), el uso de cierta indumentaria ponía de manifiesto la persona musulmana "moderada" (y "decente") frente a la persona "extremista" (e "indigna"). En cualquier caso, la flexibilidad británica ha facilitado que algunas mezquitas tomen iniciativas que difícilmente observaríamos en otros países como España (al ser interpretadas de forma negativa), tal como la edición y difusión de folletos para que las mujeres comprendan su papel en el Islam y algunos aspectos a cuidar como la vestimenta ${ }^{18}$.

${ }^{17}$ Se puede seguir la noticia en: http://www.lanacion.com.ar/893147-sin-velo-en-lasescuelas-inglesas (consultado en agosto de 2011).

18 Por ejemplo, en Londres en 2005 se entregaban folletos titulados "Women in Islam" editados por World Assembly of Muslim Youth (su web es: http://ww.wamyco.uk) en los que se explicitaba que: "In order to safeguard the moral integrity of family and society, Muslim men and women are expected to observe certain guidelines of behaviour 
A pesar de la permisibilidad británica, cierto descontento social ha llevado a apostar policías en algunas mezquitas los viernes en los horarios de mayor afluencia de creyentes a la oración.

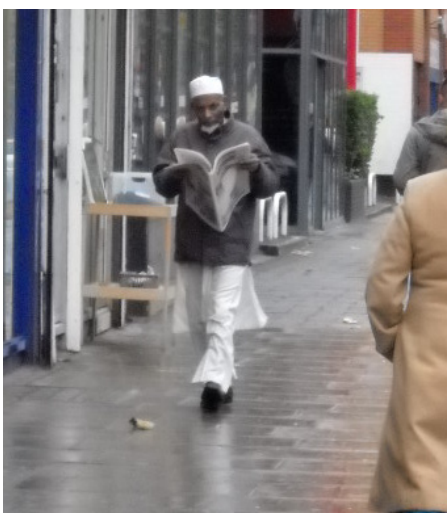

FIGURA 12.-Hombre saliendo de la mezquita East London un viernes ataviado con la indumentaria adecuada para la oración. Londres. Noviembre de 2009. Foto de Y. Aixelà.

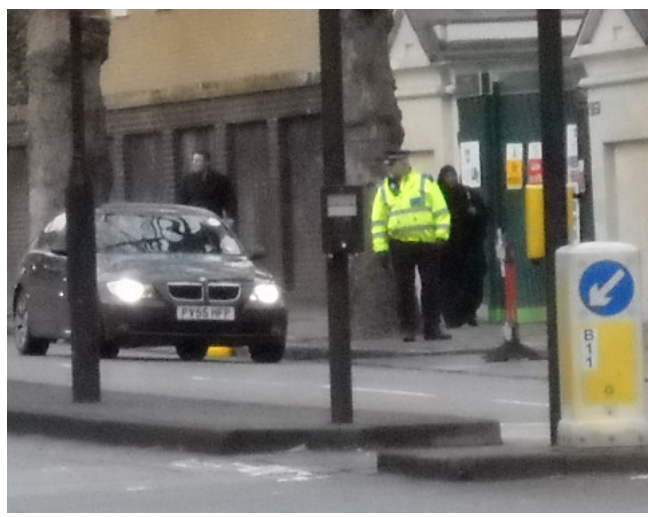

FIGURA 13.-Policía apostada durante la oración del viernes en la Mezquita Regents Park. Londres. Noviembre de 2009. Foto de Y. Aixelà.

\section{EL CASO ESPAÑOL}

En España se aprobó una normativa contra el uso del velo integral en el pleno del Ayuntamiento de Lleida (resolución del Ayuntamiento de Lleida de 25-10-2010), en la que se modificaba la anterior Ordenanza Municipal del Civismo y Convivencia (OMCIC) ${ }^{19}$. Esta iniciativa fue posteriormente

that Westerners may find restrictive. Both sexes are expected to dress modestly in loose, non-transparent clothing and avoid situation that would put them alone with members of the opposite sex, or lead to temptation or misunderstandings. Muslim women additionally cover their hair, since women are ordinarily considered to be the more attractive of the sexes. These restrictions are not observed at home among close family members, but serve to protect women's honour in public and draw attention to their personal qualitites rather than their looks... However, Muslims are saddened by the rise in the vulgar exploitation of women and the human body for marketing purposes and pornography, which inevitably result in a cheapening of sexuality and the undermining of family and spiritual life".

${ }^{19}$ Sobre el particular se puede consultar El País: http://www.elpais.com/articulo/sociedad/Lleida/multara/600/euros/mujeres/lleven/burka/elpepuespcat/20100702elpepusoc_6/Tes. Se puede leer el resultado del fallo del Tribunal Superior de Justicia de Cataluña tras el recurso desestimado de la Asociación Watani por la Libertad y la Justicia en: http:// www.acoes.es/pdf/STSJ-Cat-prohibicionvelo2011.pdf 
suspendida de forma cautelar por el Tribunal Superior de Justicia de Cataluña en enero de 2011, hasta que se ratificó en febrero del mismo año. La normativa de Lleida constituyó la primera ocasión que se prohibía el burka en España y tuvo un impacto que ha ido de lo local a lo regional y estatal, con una penalización que oscila entre los 30 y los 600 euros. Tras su aprobación en el Ayuntamiento de Lleida, con mayoría del Partido Socialista de Catalunya, Convergencia i Unió promovió acciones en el gobierno catalán y también las llevó a instancias estatales, como el senado español que, el 7 de julio de 2010, aprobó una moción, a iniciativa suya, para prohibir el uso del burka en los espacios públicos, la cual, finalmente, fue rechazada en el parlamento español ${ }^{20}$, a pesar de las iniciativas de CiU con el argumento de que había que garantizar la libertad y la seguridad:

Puig elogió las iniciativas de algunos ayuntamientos para garantizar el civismo y la convivencia en el espacio público con el objetivo de reglamentar "la tensión que se vive, con diferentes costumbres y sensibilidades que estamos integrando". El conseller ha explicado que un marco de referencia a nivel catalán debe permitir impulsar políticas de seguridad, "que son claves para garantizar la libertad y la convivencia". Asimismo, ha señalado que permitirá establecer la implicación de los Mossos d'Esquadra "para que venga a coadyuvar la responsabilidad que tienen los alcaldes" (La Vanguardia, 3 de agosto de 2011).

Aunque estas propuestas se refieren al velo integral, ha habido daños colaterales en la manera de percibir el velo que visten las mujeres magrebíes en general ${ }^{21}$. Tanto ha sido así que diversas instituciones catalanas de prestigio en la comunidad musulmana, como son Unión de Centros Islámicos y Culturales de Catalunya o la Associació Sociocultural Ibn Batuta, publicitaron un Manifiesto el 18 de junio de 2010 en el que afirmaban:

Volem reiterar que tant el burka com el nikab no responen a cap obligació religiosa sinó que en tot cas són costums i pràctiques culturals de determinades àrees geogràfiques, i que el seu ús públic en la nostra societat provoca rebuig, dificulta la convivència i transmet, a més, una imatge negativa dels musulmans.

Ciertamente, diferentes elementos se siguen combinando para el aumento de la islamofobia, y algunas mujeres empezaron hace tres años a sufrir sus

${ }^{20}$ La iniciativa quedó recogida en la prensa. Se puede consultar el ABC, en la noticia disponible en: http://www.abc.es/20100707/espana/burka-201007071245.html

${ }^{21}$ Algunas facilidades en el uso del velo se ven en una instrucción de la Dirección General de la Policía y de la Guardia Civil donde se permite que las mujeres musulmanas puedan hacerse el Documento Nacional de Identidad (DNI) con el hiyab, siempre que se les vea el rostro con claridad. Esta medida está recogida en el Real Decreto 1586/ 2009 donde se establecen las características concretas con las que deben realizarse las fotografías para el DNI. 
efectos, más allá del rechazo xenofóbico o de "anécdotas" cotidianas, como ser las últimas en ser atendidas en el mercado o recibir miradas de recelo. Algunas han recibido amenazas en la calle y agresiones verbales que, lógicamente, les han asustado y coartado su movilidad en el espacio público, por temor a que les pudiera suceder algún percance. Algunas de las que portaban al-amira negro o nikab decidieron dejar de salir de casa y otras sólo lo hacen acompañadas por hombres que las puedan defender en caso de altercado.

Ante esta realidad, ¿por qué muchas mujeres siguen llevando alguno de los velos disponibles? Las respuestas estarían cercanas a querer enfrentarse al rechazo. Y es sorprendente porque la imagen construida de estas mujeres las presenta como carentes de voluntad y fuerza y, sin embargo, muchas resisten. Para algunas, el velo es un protector, ya que el contexto en el que viven es ajeno en términos sociales, culturales y religiosos, por lo menos hasta que pasan unos años residiendo en migración. Por tanto, vestir el velo significa mantener especificidades culturales, privatizar segmentos de espacio público y eludir una integración cultural que pasa por la anulación pública de los valores propios.

\section{ALGUNAS CONCLUSIONES. TAGIYYA MASCULINO E HIYAB FEMENINO: ENTRE LA IDENTIDAD Y LA IDENTIFICACIÓN}

Algunas de las conclusiones más importantes que pueden extraerse tras la exposición son que las mujeres siguen emergiendo como la frontera social y religiosa del encuentro con personas de otras culturas, tanto en Marruecos como en España, fenómeno que cuenta hoy con el refuerzo masculino; que el uso de ciertas vestimentas promociona y consolida la identidad árabe o beréber musulmana en situación migratoria; que es difícil disociar de tradiciones socioculturales las vestimentas musulmanas, lo que agudiza las dificultades de integración del colectivo marroquí y magrebí; y finalmente que es muy relevante que el resultado de los discursos marroquí o europeo sobre las mujeres, sea que se acabe responsabilizando injustamente a las mujeres de la consolidación o estancamiento de la sociedad musulmana en sus países y en el extranjero.

Como afirmó Kilani (2000), la sociedad actual difícilmente puede mirar a sus otros sin la perspectiva histórica que traslada sus estereotipos del imaginario colectivo, más cuando el otro forma parte de las complejas miradas que se han conservado mutuamente entre Islam y Occidente (Said 1990). Así, el análisis de la construcción de la otredad marroquí permite observar que los aspectos que configuran y construyen los estereotipos sociales, habitualmente se fundamentan en lo islámico, colaborando en esa homogeneización cultural establecida entre Marruecos e Islam. 
La incidencia de "lo islámico" en la imagen de los marroquíes pone de manifiesto la consideración de las religiones como parte intrínseca de las identidades nacionales, constituyéndose como factor homogeneizador de identidades supranacionales. Ello se combina con la dificultad de concebir la ciudadanía española en otros términos que no sean los católicos o laicos, lo que puede favorecer el aumento de la islamofobia, ya que propicia la afirmación de la identidad musulmana como identidad supranacional y transnacional al sentirse rechazada. Así, construir la imagen del marroquí a través de la religión musulmana crea la diferencia esencial que genera todas las otras diferencias y que las explica al mismo tiempo: el Islam es la diferencia cultural que distinguirá, en la sociedad española, a ese sector de los inmigrantes que procede de Marruecos o del Magreb. A ello hay que sumar que la construcción de género en la región magrebí presupone la subordinación de las mujeres a los hombres, su dependencia desde el papel de esposas, hermanas e hijas, fórmula que se va a enunciar de manera reiterada para demostrar el "atraso cultural" de estas sociedades. El trasfondo de esta hipótesis es que el grado de civilización de las culturas se mide por el trato que reciben sus mujeres, con lo que el resultado es que se descalifica a la totalidad de la sociedad marroquí.

Por ello, es necesario insistir en que el uso de ciertas vestimentas no debería simplificarse en una incapacidad de ejercer derechos y deberes civiles y políticos, ya que al margen del vestido y de los significados asociados, las movilizaciones sociales siguen estando al orden del día, tal como están demostrando la Revolución de los Jazmines, y sus réplicas en África

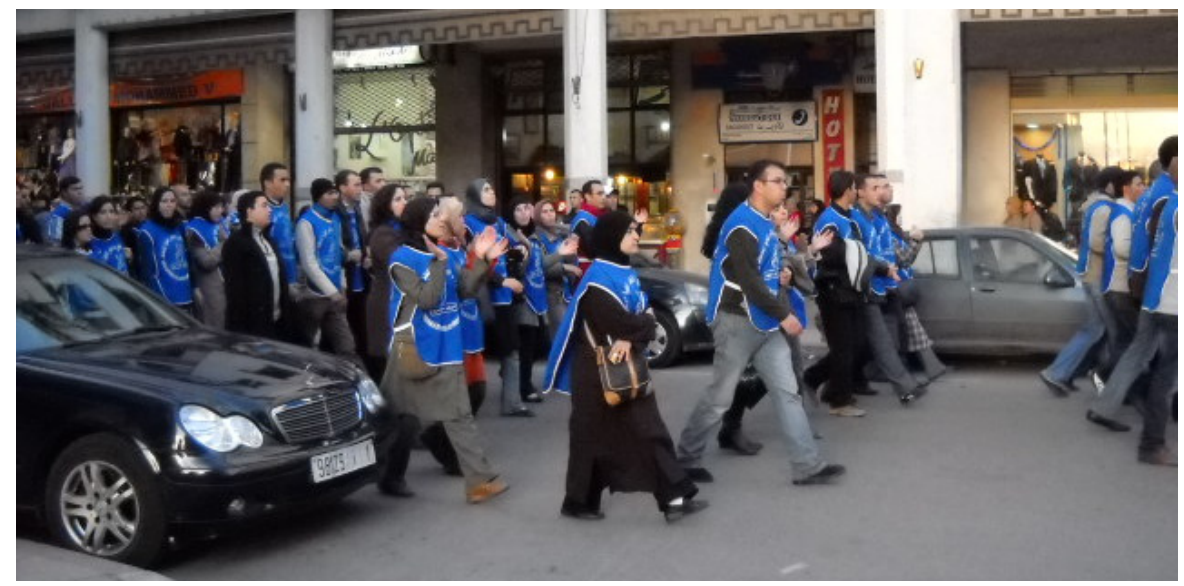

Figura 14.-Manifestación en Rabat. Diciembre de 2009. Foto de Y. Aixelà. Las jóvenes visten hiyab, los jóvenes visten a la europea. Al margen de la vestimenta, juntos reclaman derechos políticos y laborales. 
subsahariana y en Europa, habiendo supuesto - en el momento de escribir este artículo- el derrocamiento del régimen tunecino, egipcio y libio. Mientras Europa no esté preparada para desmitificar sus estereotipos, seguirán proliferando análisis erróneos de situaciones concretas en esta región, y entre sus conciudadanos residentes en Europa, en los que la presentación social del cuerpo seguirá siendo un aspecto central para evaluar el grado de "musulmanidad" de ciertos países.

\section{BIBLIOGRAFÍA CITADA}

Aguadé, J. y L. Benyahia. 2005. Diccionario árabe marroqui. Cádiz: Quorum Editores.

Aixelà, Y. 2007. "Muslims in Spain. The case of Maghrebis in Alicante". Journal for the Study of Religions and Ideologies 17: 84-100.

Aixelà, Y. 2009a. "Los códigos de familia en el mundo arabo-musulmán. Una comparación desde una perspectiva de género". The Scientific Journal of Humanistic Studies 1 (1): 1-8.

Aixelà, Y. 2009b. "Women and the law in the Arab-Muslim World". Revista Angolana de Sociologia 4: 159-176.

Aixelà, Y. 2009c. "Las elecciones marroquíes de 2007: partidos políticos y discursos de género", en Álvarez-Osorio y Zaccara (eds.), Elecciones sin elección. Procesos electorales en el Oriente Medio y en el Magreb: 301-325. Madrid: Ediciones del Oriente y el Mediterráneo.

Aixelà, Y. 2010. "La presentació social del cos al Magrib. De barbes i vels". Quaderns de l'ICA 26: 135-158.

Al Sayyad, N. Y M. Castells. 2003. ¿Europa musulmana o euro-islam? Madrid: Alianza.

Amiraux, V. 2003. "Discours voilés sur les musulmanes en Europe: comment les musulmans sont-ils devenus des musulmanes?. Social Compass 50 (1): 85-96.

Baumann, G. 1999. The multicultural Riddle. Rethinking National, Ethnic, and Religious Identities. Nueva York y Londres: Routledge.

Bourdieu, Pierre. 1972. Esquisse d'une théorie de la pratique. Ginebra: Librairie Droz.

Bourquia, R.; El Ayadi, M.; Harras y Rachik, H. (eds.). 2000. Les jeunes et les valeurs religieuses. Casablanca: Eddif.

Bourquia, R. 2000. "Les jeunes et l'expression religieuse: strategie de l'ambivalence", en Bourquia, El Ayadi, Harras y Rachik (eds.), Les jeunes et les valeurs religieuses: 27-85. Casablanca: Eddif.

Butler, J. 2006. Deshacer el género. Barcelona: Paidós.

Chebel, M. 2004. Le Corps a l'Islam. París: PUF.

El Ayadi, M. 2000. "La jeunesse et l'islam, tentative d'analyse d'un habitus religieux cultive", en Bourquia, El Ayadi, Harras y Rachik (eds.), Les jeunes et les valeurs religieuses: 87-165. Casablanca: Eddif.

Fierro, M. y F. García Fitz. 2008. El cuerpo derrotado: cómo trataban musulmanes y cristianos a los enemigos vencidos (Península Ibérica, ss. VIII-XIII). Madrid: CSIC.

González Vázquez, A. 2010. Mujeres de Yebala: Género, Islam y Alteridades en Marruecos. Tesis doctoral. Universidad de Cantabria.

Kasriel, M. 1989. Libres Femmes du Haut-Atlas? París: L'Harmattan.

Kilani, M. 2003. "Équivoques de la religion et politiques de la laïcité en Europe. Reflexions à partir de l'Islam". Archives de Sciences Sociales des Religions 121: 69-86. 
Koskennurmi-Sivonen, R.; J. Koivula y S. Maijala. 2004. "United fashions- Making a Muslim Appearance in Finland". Fashion Theory 8 (4): 443-460.

Lewis, R. 2007. "Veils and sales: Muslims and the Spaces of Postcolonial Fashion Retail". Fashion Theory 11 (4): 423-442.

Marín, M. 2001. "Signos visuales de la identidad andalusí", en M. Marín (ed.), Tejer y vestir: de la Antigüedad al Islam: 137-180. Madrid: CSIC.

Martí, J. 2008. La cultura del cos. Barcelona: UOC.

Martín Corrales, E. 2002. La imagen del Magrebi en España. Barcelona: Bellaterra.

Mateo Dieste, J. L. 2010. Salud y ritual en Marruecos. Concepciones del cuerpo y prácticas de curación. Barcelona: Bellaterra.

Moors, A. 2011. "Colonial traces? Islamic dress, gender and the public presence of Islam”, en Maussen, Vader y Moors (eds.), Colonial and Postcolonial Governance of Islam. Amsterdam: Amsterdam University Press.

Moreras, J. 1999. Musulmanes en Barcelona. Espacios y dinámicas comunitarias. Barcelona: CIDOB edicions.

Moreras, J. 2008. Simbologies en l'espai públic. Els debats sobre l'ús del hijab a Europa. Barcelona: Fundació Jaume Bofill.

Olmo, M. del. 2003. "La construcción de la confianza en el trabajo de campo. Los límites de la entrevista dirigida". Revista de Dialectología y Tradiciones Populares LVIII (1): 191-220.

Rachik, H. 2000. "Jeunesse et tolérance", en Bourquia ; El Ayadi ; Harras y Rachik (eds.), Les jeunes et les valeurs religieuses: 217-233. Casablanca: Eddif.

Ramírez, Á. 2011. La trampa del velo. El debate sobre el uso del pañuelo musulmán. Madrid: Catarata.

Roy, O. 2003. El Islam mundializado. Los musulmanes en la era de la globalización. Barcelona: Bellaterra.

Said, E. 1991 [1978]. Orientalisme. Vic: Eumo.

Saliba, T. 2002. "Introduction. Gender, Politics, and Islam", en T. Saliba y A. Howard (eds.), Gender, Politics, and Islam: 1-13. Chicago: Chicago University Press.

Schleifer, A. 1996. Motherhood in Islam. Kentucky: The Islamic Texts Society.

Serrano-Niza, D. 2005. Glosario árabe español de indumentaria según el "Kitab alMujassas" de Ibn Sidah. Madrid: CSIC.

Tazi, N. 1998. "Le désert perpétuel. Visages de la virilité au Maghreb". Cabiers Intersignes 11-12: 27-58.

Tohidi, N. 2003. "Women's rights in the Muslim World: The universal-particular interplay". HAWWA, Journal of women of Middle East and the Islamic World 1 (2): 152-188.

Tottoli, R. 2001. "Tradizioni islamiche sull'uso di tessuti e vestiti", en M. Marín (ed.), Tejer y vestir: de la Antigüedad al Islam: 43-71. Madrid: CSIC.

Vicente, T. 2001. "Imágenes marroquíes: el vestido femenino como factor constructor de identidad", en M. Marín (ed.), Tejer y vestir: de la Antigüedad al Islam: 355-365. Madrid: CSIC.

Webner, P. 1996. "The making of Muslim dissent: hybridized discourses, lay preachers, and radical rhetoric among British Pakistanis". American Ethnologist 23 (1):102-122.

Zeghal, M. 2006. Islam e islamismo en Marruecos. Barcelona: Bellaterra.

Fecha de recepción: 3 de julio de 2011

Fecha de aceptación: 6 de febrero de 2012 